\title{
Sex Differences in Etiologies of Sleep Disorders
}

\author{
Su Jung Choi ${ }^{1,2}$, Dongyeop Kim ${ }^{2}$, Yoonha Hwang ${ }^{2}$, Hyunjin Jo², Eun Yeon Joo ${ }^{2}$ \\ ${ }^{1}$ Department of Nursing, Department of Clinical Nursing Science, Samsung Medical Center, Sungkyunkwan University School of Medicine, Seoul, \\ ${ }^{2}$ Department of Neurology, Neuroscience Center, Samsung Medical Center, Sungkyunkwan University School of Medicine, Seoul, Korea
}

\author{
성별에 따른 수면장애의 원인 질환 분석

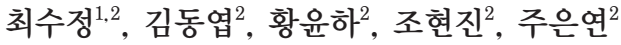 \\ 삼성서울병원 간호부, 성균관대학교 임상간호대학원, ${ }^{1}$ 성균관대학교 의과대학 삼성서울병원 신경과, 뇌신경센터 ${ }^{2}$
}

\section{Received October 30, 2020 \\ Revised November 23, 2020 \\ Accepted December 3, 2020}

Address for correspondence

Eun Yeon Joo, MD, PhD

Department of Neurology,

Neuroscience Center,

Samsung Medical Center,

Sungkyunkwan University

School of Medicine, 81 Irwon-ro,

Gangnam-gu, Seoul 06351, Korea

Tel: $+82-2-3410-3597$

Fax: $+82-2-3410-0052$

E-mail: eunyeon.joo@gmail.com
Objectives: To investigate the etiologies of sleep disorders according to sex. Methods: We enrolled 1,270 patients who complained of insomnia $(n=328)$ or sleep apnea $(n=942)$ for more than 6 months and classified them into primary insomnia (PI, $n=120$ ), comorbid obstructive sleep apnea with insomnia (COMISA, $\mathrm{n}=146$ ), and obstructive sleep apnea (OSA, $\mathrm{n}=884$ ) groups based on their polysomnography (PSG) findings, demographics, sleep-related symptoms, and questionnaire results (Insomnia Severity Index and Epworth Sleepiness Scale). Results: The highest prevalence of females was observed in PI (71.7\%), and the lowest in the OSA group (15.6\%). Males were more prevalent than females in the COMISA group (58.2\% vs. $41.8 \%)$. Regarding the etiology of insomnia, half of the male patients with complaints of insomnia had OSA, while only one-third of the females had OSA. Thirteen percent of female who complained of OSA-related symptoms were diagnosed as normal. There were few differences in PSG data between female and male patients in the PI and COMISA groups. Females with OSA showed longer total sleep time than males with OSA in PSG. The self-reported questionnaire responses of patients in the COMISA and PI groups were similar, and PSG data of patients in the COMISA and OSA groups were comparable regardless of sex. Conclusions: Females and males have different sleep perceptions and sleep-related complaints. Thus, PSG must be carried out to clarify the etiology of sleep disorders and ensure appropriate treatment is provided.

J Sleep Med 2020;17(2):138-147

Key Words: Insomnia, Obstructive sleep apnea, Symptom, Polysomnography, Sex.
서 론

불면증(insomnia)과 폐쇄수면무호흡증(obstructive sleep apnea, OSA)은 성인에서 가장 흔한 수면장애로, 수면장애, 주간 기능 저하, 정서변화 등 개인의 삶의 질에 영향을 주는 질환이다. ${ }^{1}$ 불면증 유병률은 $10 \sim 15 \%$ 로 그 중 절반이 만성 경과를 보이며, ${ }^{2}$ 여성이 남성보다 1.4 배 정도 높고, ${ }^{3}$ 노인에서 더 증가하는데, 국내 60 세 이상 노령인구에서 $1 / 3$ 이상이 불 면증을 겪는다고 보고되고 있다. ${ }^{4}$ 불면증은 주관적 수면장애 증상에 근거해 임상판단에 의해 진단을 내리기 때문에 모든

This is an Open Access article distributed under the terms of the Creative Commons Attribution Non-Commercial License (https://creativecommons.org/licenses/by-nc/4.0) which permits unrestricted non-commercial use, distribution, and reproduction in any medium, provided the original work is properly cited.
환자에서 수면다원검사를 시행하지는 않는다. ${ }^{1}$ 하지만, 중년 층 이상에서는 폐쇄수면무호흡이나 주기적사지운동증과 연 관된 불면증상도 상당히 많기 때문에 수면다원검사의 적응 증은 연령에 따라 달라질 수 있다. 특히 폐쇄수면무호흡증은 고혈압, 당뇨, 심장질환, 뇌졸중, 발기부전 등과도 연관이 있 어 적절한 치료를 받지 못하면 정상인에 비해 심혈관계 질환 으로 인한 위험성이 2 3배 증가하므로 조기 진단과 치료가 중요하다. ${ }^{5}$

본 연구팀은 이전 연구에서 불면으로 내원한 환자의 $25.8 \%$ 는 일차성 불면증(primary insomnia, PI), $18.4 \%$ 는 OSA가 동 반된 불면증(comorbid insomnia with obstructive sleep apnea, COMISA)으로 보고했다. ${ }^{6}$ COMISA의 비율이 29 67\% 까지 보고한 선행연구보다 낮았는데, 이는 인종적, 문화적 차 
이와 관련이 있을 것으로 추정했다. ${ }^{7}$ 지난 2018년 7월부터 $\mathrm{OSA}$ 환자에서 수면다원검사의 급여가 인정되면서, 불면증 으로 왔으나 OSA의 동반이 의심되는 경우 수면다원검사를 받을 수 있게 되었다. 앞으로 COMISA의 진단율이 더 증가 할 것으로 예상된다.

$\mathrm{OSA}$ 는 남성이 여성보다 2배 이상 많은 것으로 알려져 있 으나 갱년기를 지나면서 여성에서의 유병율이 남성과 비슷 해진다. ${ }^{8}$ 그러나 OSA의 주 호소나 수면다원검사 소견은 성 별에 따라 다를 수 있다. ${ }^{9}$ 불면증의 경우도 성별에 따른 임상 양상, 수면다원검사 및 치료에 대한 반응이 다르다고 보고되 었으나, $3,10,11$ 국내에서는 수면장애의 성별에 따른 특성에 대 한 연구가 거의 되어 있지 않다.

이에 본 연구는 불면 또는 폐쇄수면무호흡 관련 증상으로 내원한 환자들의 원인질환이 성별에 따라 차이가 있을 것으 로 가정하고 이를 증명하기 위하여 불면증 또는 수면호흡장 애를 주소로 내원한 환자들의 수면다원검사와 수면설문지 및 병력을 바탕으로 최종 진단된 수면장애 분포를 성별에 따라 나누어 비교하고, 이들 중 주요 진단군인 PI, COMISA, $\mathrm{OSA}$ 군을 대상으로 각 진단군 내에서 일반적 특성이나 수면 다원검사결과가 성별에 따라서 차이가 있는지를 확인하고자 한다. 부가적으로 PI, COMISA, OSA군간에 일반적 특성이 나 수면다원검사 결과가 차이가 있는지를 남녀를 나누어 각 각 비교하였다. 본 연구 결과를 통해 수면장애호소 환자들의 성별에 따라 일반적 특성과 주관적 호소 증상이 차이가 있 는지를 확인하여 임상적으로 환자를 평가하는데 도움이 되 고자 하며, 주관적 특성만으로는 수면장애 진단에 감별이 어
렵다면 객관적인 수면다원검사에서는 성별에 따라 어떤 차이 를 보이는지를 파악하여 치료적 접근에 도움이 되고자 한다.

\section{방 법}

\section{대 상}

본 연구는 의무기록을 이용한 후향적 조사로, 2018년 11월 1일 2020년 2월 10일까지 6개월 이상 불면증이나 폐쇄수면 무호흡 관련증상이 지속되어 삼성서울병원에서 수면다원검 사를 받은 18 세 이상 성인 환자 중, 설문작성이 가능한 내국 인을 대상으로 하였고, 자살 사고를 지닌 주요 우울장애, 신 체화장애, 조현병 등을 비롯한 주요 정신질환, 임산부, 수유 부, 교대근무자, 분절 수면다원검사(split-night polysomnography)를 받은 환자는 제외하였다. 총 1,270 명의 환자가 선정기준에 적합하였는데, 수면클리닉에 내원 당시 주관적 주 호소증상이 불면증인 경우가 328명이고, 폐쇄수면무호흡 관련증상인 경우가 942명이었다. 이들 중 PI, COMISA, OSA 군으로 진단된 1,150명을 최종분석에 포함시켰다(Fig. 1).

본 연구에 사용된 연구 기준, 방법 및 평가는 삼성서울병원 기관윤리심의위원회의 심의(승인번호 2020-03-020)와 동의 면제 승인을 획득하였으며, 기관윤리심의위원회의 관리감독 하에 시행되었다.

\section{설문지}

한글판 불면증 심각도지수(Insomnia Severity Index, ISI) 와 엡워스 주간졸림증 척도(Epworth sleepiness scale, ESS)

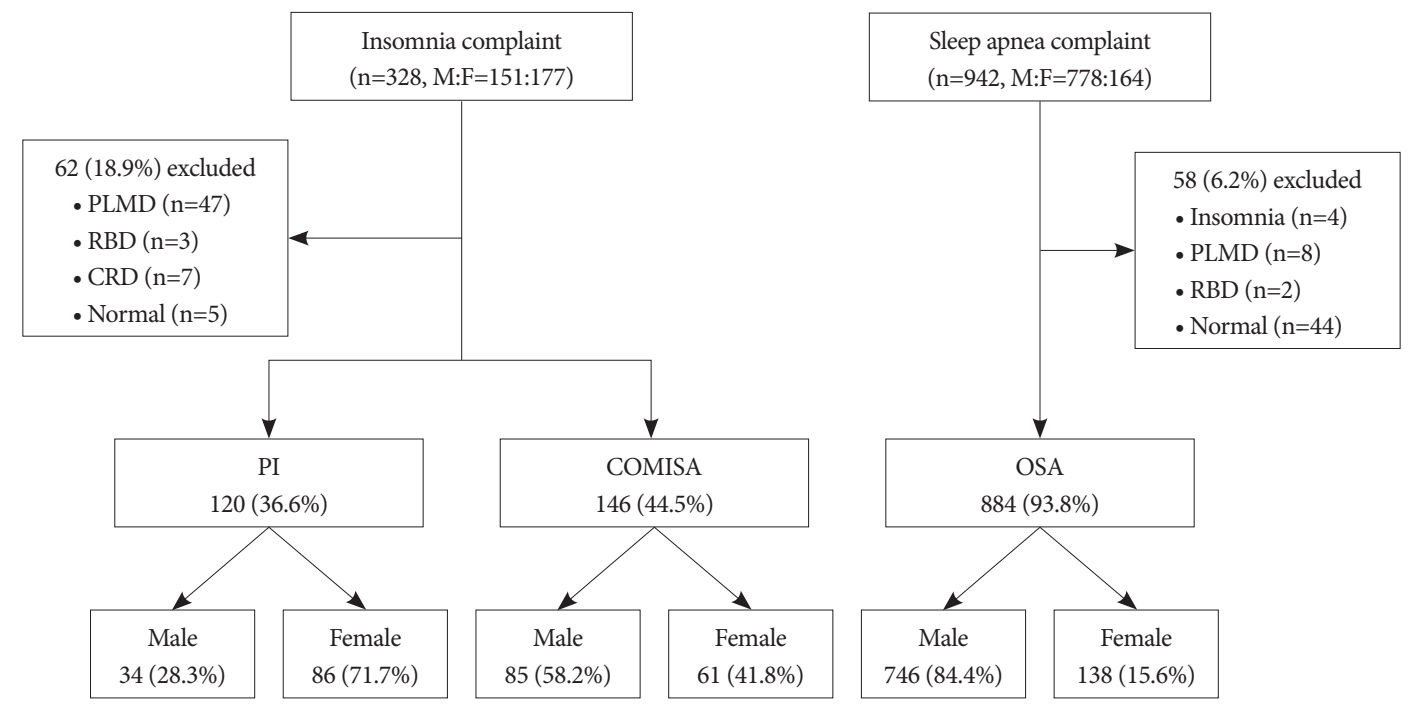

Figure 1. Enrollment log of the study. We enrolled 1,270 adult patients who have complaint symptoms of insomnia $(n=328)$ or sleep apnea $(n=942)$ for more than six months. Patients who diagnosed other sleep disorders except insomnia and obstructive sleep apnea (OSA) were excluded. Finally, the patients were classified into primary insomnia ( $\mathrm{PI}, \mathrm{n}=120)$, comorbid obstructive sleep apnea in insomnia (COMISA, $n=146$ ), and OSA, n=884) groups by analyzing their polysomnography, habitual sleep, subjective sleep related symptom as the etiologies. PLMD: periodic limb movement disorder, RBD: REM sleep behavior disorder, CRD: circadian rhythm disorder. 
를 사용하였다. ${ }^{12,13}$ 잠들기 어려움, 잠을 유지하기 어려움, 코 골이 여부, 수면 중 무호흡 여부, 낮잠을 자는지 여부를 '예/ 아니오'로 응답하게 하였다. 설문지는 수면다원검사를 위해 내원한 날 검사실에서 작성되었다. 그 외 의무기록 검토를 통해 수면제 복용 여부를 조사하였다.

\section{수면다원검사}

검사장비는 Embla N7000(Medcare-Embla ${ }^{\circledR}$, Reykjavik, Iceland)이었다. 기본 검사항목으로 6채널의 뇌파(C3-A2, C4-A1, F3-A2, F4-A1, O3-A2, O2-A1)와 4채널의 안전위 도(electro-oculogram), 1채널의 턱근전도(chin EMG)를 기 록하여 수면과 각성 빈도를 측정하였다. 호흡관련 측정을 위 해서 압력센서를 이용하여 비강공기압을 측정하였다. 호흡 노력을 보기 위해 흥곽과 복부벨트를 이용하여 호흡움직임 을 측정하였다. Oximetry를 이용하여 검지손가락에서 산소 포화도를 측정하였고, 소리센서로 코골이 강도를 측정하였 다. 다리 움직임을 보기 위해 2채널의 양측 전경골근(anterior tibialis)의 근전도를 측정하였다. 수면자세를 확인하는 체 위 센서와 심전도를 함께 측정하며 동시에 비디오를 기록하 여 수면 중 행동장애나 자세를 기록하였다.

수면양상, 호흡지수, 각성 등에 대한 판독은 American Academy of Sleep Medicine(AASM) Manual에 따라 판독 되었다..$^{14}$ 수면양상은 총 침상시간(time in bed, TIB), 총 수 면시간(total sleep time, TST), 수면잠복기(sleep latency, SL), 렘수면잠복기(rapid eye movement sleep latency, REML), 입면 후 각성시간(wakefulness after sleep onset, WASO), 수면 효율(sleep efficiency)로 측정하였고, 총 각성지수(total arousal index, total ArI) 등을 평가하였다. 총 각성지수 중 호흡각성지수(respiratory arousal index, resp. ArI), 호흡노력 각성지수(respiratory effort related arousal index, RERA I), 자발각성지수(spontaneous arousal index, spont. ArI), 운동 각성지수(movement arousal index, MAI)를 추가로 나누어 분석하였다. 무호흡(apnea)은 10초 이상 호흡이 멈추는 것으 로 비강의 온도와 압력센서를 통해 공기흐름이 $90 \%$ 이상 감 소하는 상태를 말하며, 호흡저하(hypopnea)는 공기흐름이 10 초 이상, $30 \%$ 이상 감소를 보이면서 산소포화도가 $4 \%$ 이 상 떨어지는 경우, 또는 뇌파 상 각성이 관찰되는 경우로 정 의하였다. 무호흡-저호흡지수(apnea-hypopnea index, AHI) 는 무호흡과 저호흡을 합한 빈도를 시간당으로 계산하였다.

\section{대상자 분류}

병력, 설문지, 수면다원검사결과를 바탕으로 수면장애의 원인질환을 다음의 세 질환으로 분류했다(PI vs. COMISA vs. OSA). 세부 분류에 대한 자세한 내용은 이전 연구에서 보고한 바 있으며, 본 연구에서는 연구 목표에 따라 다음과 같이 정의했다. ${ }^{15} \mathrm{PI}$ 군은 $\mathrm{AHI}$ 가 시간당 15 미만이며 각성지 수의 $50 \%$ 이상이 특별한 원인 없이 발생하고 병력에서 하지 불안증후군 혹은 주기사지운동장애, 렘수면행동장애가 없 는 경우로 정하였다. COMISA군은 불면증을 주소로 내원하 였으나 $\mathrm{AHI}$ 가 시간당 5 이상이고, 각성지수의 $50 \%$ 이상이 수면호흡장애(무호흡, 저호흡, 코골이)에 의하며 병력에서 기타 수면장애가 없는 경우로 하였다. OSA군은 수면호흡장 애를 주소로 내원하였고 $\mathrm{AHI}$ 가 시간당 5 이상이면서 관련 불편감이나 장애(예: 주간졸음, 피로, 코골이, 고혈압, 인지기 능 저하 등)가 존재하거나, AHI가 15 이상인 AASM 기준에 추가하여, 각성지수의 $50 \%$ 이상이 수면호흡장애인 경우로 하였다. ${ }^{1}$

그 외 불면증 또는 폐쇄수면무호흡증 관련증상을 호소하는 연구대상 환자 중 수면다원검사에서 각성의 주요 원인이 불 가역적 다리 움직임으로 인한 MAI가 $5 / \mathrm{h}$ 이상인 경우는 주 기적 사지운동증(periodic limb movement disorder, PLMD) 으로 분류하였고, 렘수면무긴장소실(rapid eye movement sleep without atonia)이 있는 경우는 렘수면행동장애로 분 류하였다. ${ }^{16}$ 수면다원검사에서 특별한 이상소견이 발견되지 않는 경우는 정상군으로 분류하였고, 기타 병력과 수면일지 나 액티그래피 기록에서 일주기유형에 이상소견을 보이는 경우 일주기리듬장애로 분류하였다. ${ }^{17}$

진단 분류는 2 명의 수면전문의가 각각 시행하였으며, 이 견이 있을 경우 토의를 거쳐 최종 판단하였다.

\section{자료분석 방법}

수집된 자료는 유의수준 0.05 로 하여 SPSS WIN version 18.0(SPSS Inc, Chicago, IL, USA)을 이용하여 다음과 같이 분석하였다. 불면증과 수면호흡장애 증상 별 최종 수면장애 진단 분포는 빈도와 백분율을 제시하고, 성별에 따른 차이는 기대도수가 0.5 이하인 집단이 있어 Fisher's exact test로 분 석하였다. 최종적으로 $\mathrm{PI}, \mathrm{COMISA}, \mathrm{OSA}$ 로 분류된 대상자 의 일반적 특성과 설문지 및 주관적 증상의 서술적 통계는 평 균과 표준편차 또는 빈도와 백분율로 제시하였고, 각 군에서 성별에 따른 차이는, 범주형 변수의 경우에는 chi-squared test 또는 Fisher's exact test로 분석하였고, 연속형 변수의 경우에는 t-test로 분석하였다. 수면다원검사 결과의 성별에 따른 차이는 OSA군에서 남녀간 폐쇄수면무호흡 중증도 분 포에 차이가 있어 남녀간 비교 결과는 일반선형모형 (general linear model)을 이용하여 AHI값을 공변량으로 처리하여 공분산분석(analysis of covariance)을 시행하였다. 
PI, COMISA, OSA 세 군간 차이는 범주형 변수의 경우에 는 chi-squared test 또는 Fisher's exact test로 분석하였고, 연속형 변수의 경우 일원배치분산분석(one-way analysis of variance analysis)와 사후검정(Scheffe test)으로 검증하였다.

\section{결 과}

\section{성별에 따른 불면증 또는 수면호흡장애 증상 별 최종 진단 분류}

전체 대상자 중 불면증을 주 호소로 하는 환자는 328명이 고, 폐쇄수면무호흡 관련증상을 호소하는 환자는 942명이었 다. 불면증 증상군과 폐쇄수면무호흡 증상군 환자들을 각각 남성과 여성으로 나누어 최종 진단명을 분석한 결과는 Fig. 2 와 같다. 먼저 남성 불면증 증상군 151 명에서 최종 진단명이 $\mathrm{OSA}$ 인 경우가 85 명 $(56.3 \%)$ 으로 가장 많았고, PI가 34명 (22.5\%), PLMD가 25명(16.6\%) 순으로 나타났고, 여성 불면 증 증상군 177 명 중에서는 PI군이 86명(48.6\%)으로 가장 많 았고, OSA군이 61명(34.5\%), PLMD가 22(12.4\%)순으로 확 인되었고, 불면증 증상군에서 최종 진단군 분포는 성별에 따 라 유의한 차이를 보였다 $\left(\chi^{2}=29.30, p<0.001\right)$.

폐쇄수면무호흡 증상군 942명을 대상으로 성별에 따른 진 단명 분포를 확인한 결과, 남성에서는 OSA가 746명(95.9\%) 으로 가장 많았고, 정상군이 23(3.0\%), PLMD 진단이 5명(0.6\%) 순으로 나타났고, 여성 폐쇄수면무호흡 증상군 164 명 중 OSA로 진단된 환자는 138명(84.1\%), 정상군이 21명(12.8\%),
PLMD이 3명(1.8\%) 순으로 나타나, 폐쇄수면무호흡 증상군 에서 최종 진단군 분포는 성별에 따라 유의한 차이가 있는 것으로 확인되었다 $\left(\chi^{2}=29.27, p<0.001\right)$.

\section{PI, COMISA, OSA 군 내에서 성별에 따른 일반적 특성 비교}

PI군에서는 여성이 남성보다 수면제 복용비율이 높고, ISI 점수가 더 높고, 입면장애 호소 빈도가 높고, 평소 SL이 유의 하게 더 긴 것으로 나타났다. COMISA군에서는 여성이 남성 보다 나이가 더 많고 ISI 점수가 높으며, 입면장애 호소 빈도 가 높고, 평소 SL이 길고 수면시간은 더 짧은 것으로 보고되 었고, 낮잠을 자는 빈도는 남성이 $30.6 \%$ 로 여성의 $14.8 \%$ 보다 유의하게 많았다. OSA군의 경우에도 여성이 남성보다 나이 가 더 많고, 수면제 복용 비율이 높고, ISI 점수가 높고, 입면 장애 호소 빈도가 높았으며, 평소 SL이 유의하게 더 긴 것으 로 보고하였고, 무호흡을 목격하는 빈도나 낮잠을 자는 빈도 는 남성이 여성보다 더 높은 것으로 조사되었다(Table 1).

\section{$\mathrm{PI}, \mathrm{COMISA}, \mathrm{OSA}$ 군 내에서 성별에 따른 수면다원검사 결과 비교}

$\mathrm{AHI}$ 를 공변량으로 처리한 후 수면다원검사 결과를 성별에 따라 비교한 결과 PI군에서는 total ArI, resp. ArI, RERA I, MAI, 주기적 사지 운동지수(periodic limb movement index, PLMI)와 수면검사 다음날 주관적으로 인지하는 수면잠복 기(perceived SL)가 성별에 따라 유의한 차이가 있는 것으로

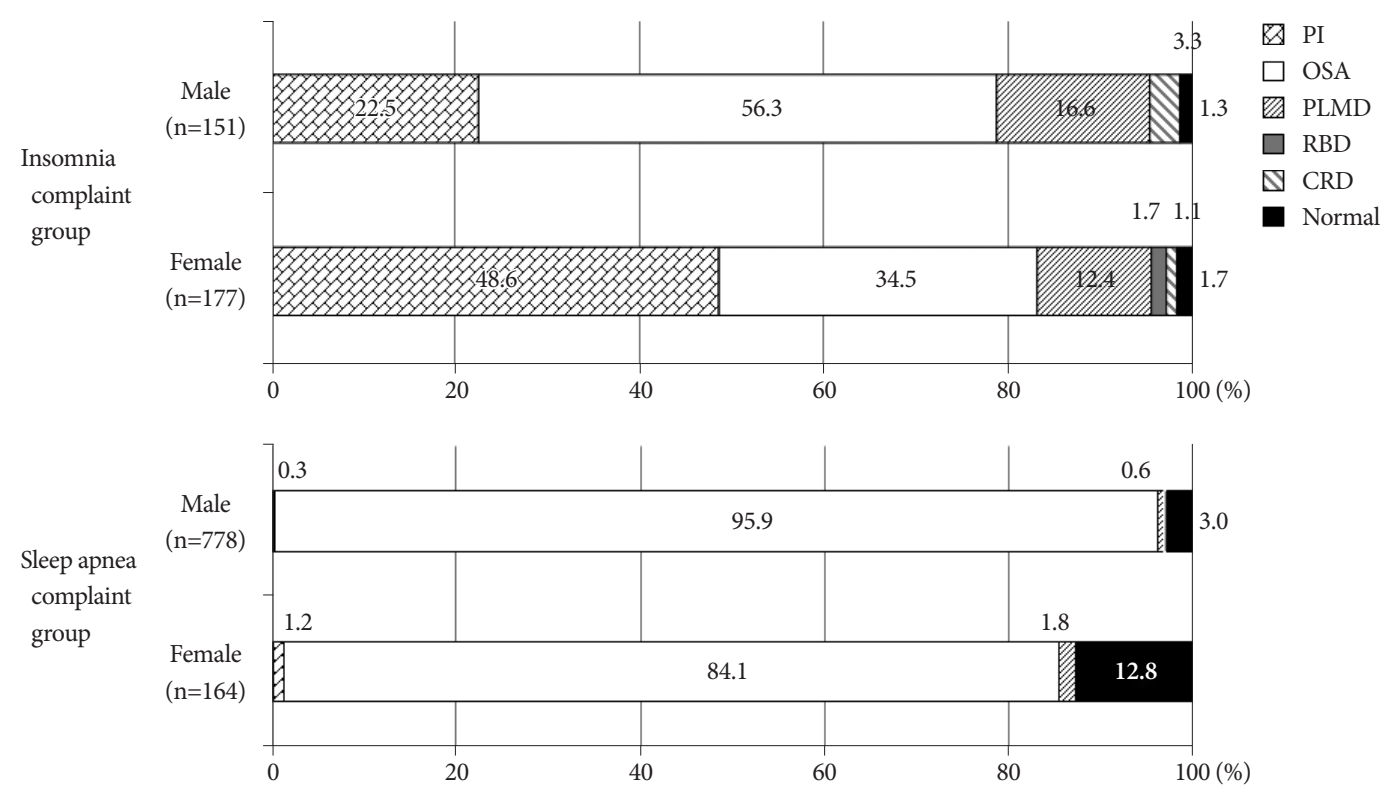

Figure 2. Distribution of sleep disorders according to subjective sleep complaints. When we analyzed the distribution of sleep diagnosis who complaint insomnia symptoms, $34(22.5 \%)$ of males were diagnosed with PI and $85(56.3 \%)$ were with OSA, while $48.6 \%$ of females $(n=86)$ were revealed to have PI and $34.5 \%(n=61)$ were to have OSA as an etiology of insomnia. In case of sleep apnea complaints, most of patients were diagnosed with OSA both male and female. PI: primary insomnia, OSA: obstructive sleep apnea, PLMD: periodic limb movement disorder, RBD: REM sleep behavior disorder, CRD: circadian rhythm disorder. 
조사되었다 $(p<0.05)$. COMISA군에서는 REML, total ArI 및 resp. ArI 지표가 성별에 따른 차이를 보였고, OSA군에서 는 TIB, TST, REML, AHI, total ArI, resp. ArI, RERA I, spont. ArI 지표가 성별에 따라 유의한 차이가 있는 것으로 조사되었다(Table 2).

\section{남녀 각각에서 PI, COMISA, OSA 질환간 일반적 특성 비교}

먼저 남성에서는 평소 낮잠을 자는 빈도를 제외한 모든 특성이 질환에 따라 유의한 차이를 보였는데, 사후분석 결과 나이는 $\mathrm{COMISA}$ 군이 가장 많았고, $\mathrm{BMI}$ 는 $\mathrm{OSA}$ 군이 가장 높았고, ISI 점수는 PI군과 COMISA군이 OSA군보다 높았 으며, $\mathrm{ESS}$ 점수는 OSA군이 COMISA군보다 높았고, 평소 $\mathrm{SL}$ 은 PI군과 COMISA군이 OSA군보다 길었고, 수면시간은 반대로 OSA군이 가장 긴 것으로 나타났다.
여성의 경우 $\mathrm{BMI}$ 를 제외한 모든 특성에서 질환간 유의한 차이를 보였는데, 사후분석 결과 나이는 COMISA군이 가장 많았고, OSA군에서 ISI 점수가 가장 낮고, ESS 점수가 가장 높았으며, 평소 SL이 가장 짧고, 평소 TST는 가장 긴 것으로 보고하였다(Table 1).

\section{남녀 각각에서 PI, COMISA, OSA 질환간 수면다원검사 결과 비교}

남성의 경우 MAI를 제외한 모든 지표가 질환간 유의한 차 이를 보였는데, 사후분석 결과 OSA군에서 TIB가 PI군보다 짧고, TST와 SE는 COMISA보다 길거나 높았으며, SL과 perceived SL은 다른 두 군보다 짧았고, REML과 WASO는 COMISA군보다 짧았고, perceived TST는 가장 긴 것으로 나타났다. AHI, total ArI, resp. ArI는 PI군이 가장 낮았으며,

Table 1. Comparison of general characteristics and habitual sleep of three groups $(n=1,150)$

\begin{tabular}{|c|c|c|c|c|c|c|c|c|c|}
\hline Variables & Sex & $\begin{array}{c}\mathrm{PI}^{\mathrm{a}} \\
(\mathrm{n}=120) \\
\mathrm{M}: \mathrm{F}=34: 86\end{array}$ & $\begin{array}{c}p \\
\text { (between } \\
\text { sex) }\end{array}$ & $\begin{array}{c}\text { COMISA }^{\mathrm{b}} \\
(\mathrm{n}=146) \\
\mathrm{M}: \mathrm{F}=85: 61\end{array}$ & $\begin{array}{c}p \\
\text { (between } \\
\text { sex) }\end{array}$ & $\begin{array}{c}\text { OSA }^{c} \\
(\mathrm{n}=884) \\
\mathrm{M}: \mathrm{F}=746: 138\end{array}$ & $\begin{array}{c}p \\
\text { (between } \\
\text { sex) }\end{array}$ & $\begin{array}{c}p \\
\text { (between } \\
3 \text { group) }\end{array}$ & Scheffe \\
\hline \multirow[t]{2}{*}{ Age (yr) } & $\mathrm{M}$ & $52.75 \pm 13.06$ & 0.088 & $60.62 \pm 12.25$ & 0.018 & $52.67 \pm 12.99$ & $<0.001$ & $<0.001$ & $\mathrm{~b}>\mathrm{a}, \mathrm{c}$ \\
\hline & $\mathrm{F}$ & $56.93 \pm 11.48$ & & $65.16 \pm 9.84$ & & $58.06 \pm 12.42$ & & $<0.001$ & $\mathrm{~b}>\mathrm{a}, \mathrm{c}$ \\
\hline \multirow[t]{2}{*}{ BMI $\left(\mathrm{kg} / \mathrm{m}^{2}\right)$} & M & $23.81 \pm 2.79$ & 0.667 & $25.40 \pm 3.86$ & 0.177 & $26.95 \pm 3.99$ & 0.137 & $<0.001$ & $\mathrm{a}, \mathrm{b}<\mathrm{c}$ \\
\hline & $\mathrm{F}$ & $24.74 \pm 12.35$ & & $24.52 \pm 3.77$ & & $26.21 \pm 5.56$ & & 0.257 & \\
\hline \multirow{2}{*}{$\begin{array}{l}\text { History of hypnotics } \\
\text { or sleep medication }\end{array}$} & M & $15(44.1)$ & $<0.001$ & $43(50.6)$ & 0.160 & $91(12.2)$ & 0.019 & $<0.001$ & \\
\hline & $\mathrm{F}$ & $69(80.2)$ & & $38(62.3)$ & & $27(19.6)$ & & $<0.001$ & \\
\hline \multirow[t]{2}{*}{ ISI } & M & $14.61 \pm 4.93$ & 0.006 & $14.91 \pm 5.03$ & 0.025 & $9.41 \pm 5.41$ & 0.004 & $<0.001$ & $a, b>c$ \\
\hline & $\mathrm{F}$ & $17.64 \pm 5.43$ & & $17.00 \pm 5.79$ & & $10.89 \pm 5.59$ & & $<0.001$ & $a, b>c$ \\
\hline \multirow[t]{2}{*}{ ESS } & M & $7.94 \pm 4.54$ & 0.087 & $7.82 \pm 5.15$ & 0.607 & $9.80 \pm 4.80$ & 0.397 & $<0.001$ & $\mathrm{~b}<\mathrm{c}$ \\
\hline & $\mathrm{F}$ & $6.29 \pm 4.79$ & & $7.34 \pm 5.94$ & & $9.42 \pm 5.03$ & & $<0.001$ & $\mathrm{a}, \mathrm{b}<\mathrm{c}$ \\
\hline \multirow[t]{2}{*}{ Sleep onset problem } & M & $24(70.6)$ & 0.049 & $57(67.1)$ & 0.025 & $146(19.6)$ & 0.004 & $<0.001$ & \\
\hline & $\mathrm{F}$ & $74(86.0)$ & & $51(83.6)$ & & $42(30.4)$ & & $<0.001$ & \\
\hline \multirow{2}{*}{$\begin{array}{l}\text { Sleep maintenance } \\
\text { problem }\end{array}$} & M & $29(85.3)$ & $>0.999^{*}$ & $58(68.2)$ & 0.103 & $359(48.1)$ & 0.303 & $<0.001$ & \\
\hline & $\mathrm{F}$ & $74(86.0)$ & & $49(80.3)$ & & $73(52.9)$ & & $<0.001$ & \\
\hline \multirow[t]{2}{*}{ Snoring symptom } & M & $19(55.9)$ & 0.081 & $57(67.1)$ & 0.819 & $680(91.2)$ & 0.625 & $<0.001^{*}$ & \\
\hline & $\mathrm{F}$ & $33(38.4)$ & & $42(68.9)$ & & $124(89.9)$ & & $<0.001$ & \\
\hline \multirow[t]{2}{*}{ Witness of apnea } & M & $6(17.6)$ & $0.189^{*}$ & $43(50.6)$ & 0.179 & $587(78.7)$ & $<0.001$ & $<0.001$ & \\
\hline & $\mathrm{F}$ & $7(8.1)$ & & $24(39.3)$ & & $80(58.0)$ & & $<0.001$ & \\
\hline \multirow[t]{2}{*}{ Nap } & M & $6(17.6)$ & $0.563^{*}$ & $26(30.6)$ & 0.027 & $269(36.1)$ & 0.024 & 0.061 & \\
\hline & $\mathrm{F}$ & $11(12.8)$ & & $9(14.8)$ & & $36(26.1)$ & & 0.029 & \\
\hline \multirow[t]{2}{*}{ Habitual SL, min } & M & $39.34 \pm 27.73$ & $<0.001$ & $49.80 \pm 36.89$ & 0.001 & $23.99 \pm 27.64$ & 0.017 & $<0.001$ & $a, b>c$ \\
\hline & $\mathrm{F}$ & $67.80 \pm 54.08$ & & $84.04 \pm 67.73$ & & $31.98 \pm 36.71$ & & $<0.001$ & $a, b>c$ \\
\hline \multirow[t]{2}{*}{ Habitual TST, h } & M & $6.10 \pm 1.56$ & 0.321 & $6.15 \pm 1.57$ & 0.003 & $6.68 \pm 1.19$ & 0.559 & $<0.001$ & $\mathrm{a}, \mathrm{b}<\mathrm{c}$ \\
\hline & $\mathrm{F}$ & $5.74 \pm 1.88$ & & $5.20 \pm 1.88$ & & $6.76 \pm 1.52$ & & $<0.001$ & $\mathrm{a}, \mathrm{b}<\mathrm{c}$ \\
\hline
\end{tabular}

Values are expressed as mean \pm standard deviation or numbers (\%). ${ }^{*}$ Fisher's exact test. PI: primary insomnia, COMISA: comorbid insomnia with obstructive sleep apnea, OSA: obstructive sleep apnea, BMI: body mass index, ISI: Insomnia Severity Index, ESS: Epworth Sleepiness Scale, SL: sleep latency, TST: total sleep time 
Table 2. Comparison of polysomnograpy data of three groups $(n=1,150)$

\begin{tabular}{|c|c|c|c|c|c|c|c|c|c|}
\hline Variables & Sex & $\begin{array}{c}\mathrm{PI}^{\mathrm{a}} \\
(\mathrm{n}=120) \\
\mathrm{M}: \mathrm{F}=34: 86\end{array}$ & $\begin{array}{c}p \\
\text { (between } \\
\text { sex) }\end{array}$ & $\begin{array}{c}\text { COMISA }^{\mathrm{b}} \\
(\mathrm{n}=146) \\
\mathrm{M}: \mathrm{F}=85: 61\end{array}$ & $\begin{array}{c}p \\
\text { (between } \\
\text { sex) }\end{array}$ & $\begin{array}{c}\text { OSA }^{c} \\
(\mathrm{n}=884) \\
\mathrm{M}: \mathrm{F}=746: 138\end{array}$ & $\begin{array}{c}p \\
\text { (between } \\
\text { sex) }\end{array}$ & $\begin{array}{c}p \\
\text { (between } \\
3 \text { group) }\end{array}$ & Scheffe \\
\hline \multirow[t]{2}{*}{ TIB (h) } & M & $7.39 \pm 0.76$ & 0.148 & $7.01 \pm 0.91$ & 0.136 & $6.99 \pm 0.85$ & $<0.001$ & 0.026 & $a>c$ \\
\hline & $\mathrm{F}$ & $7.61 \pm 0.68$ & & $7.27 \pm 0.99$ & & $7.40 \pm 0.90$ & & 0.046 & - \\
\hline \multirow[t]{2}{*}{ TST (h) } & M & $5.68 \pm 1.01$ & 0.214 & $5.30 \pm 1.17$ & 0.078 & $5.75 \pm 1.07$ & $<0.001$ & 0.002 & $\mathrm{~b}<\mathrm{c}$ \\
\hline & $\mathrm{F}$ & $5.96 \pm 1.00$ & & $5.67 \pm 1.11$ & & $6.22 \pm 0.98$ & & 0.002 & $\mathrm{~b}<\mathrm{c}$ \\
\hline \multirow[t]{2}{*}{ SL (min) } & M & $18.95 \pm 28.99$ & 0.112 & $16.52 \pm 20.69$ & 0.218 & $9.29 \pm 14.71$ & 0.099 & $<0.001$ & $a, b>c$ \\
\hline & $\mathrm{F}$ & $28.53 \pm 35.87$ & & $21.45 \pm 24.61$ & & $11.52 \pm 11.44$ & & $<0.001$ & $a, b>c$ \\
\hline \multirow[t]{2}{*}{ REML (min) } & M & $115.22 \pm 77.07$ & 0.803 & $131.63 \pm 85.10$ & 0.010 & $103.27 \pm 61.10$ & 0.008 & 0.001 & $\mathrm{~b}>\mathrm{c}$ \\
\hline & $\mathrm{F}$ & $120.25 \pm 64.19$ & & $127.92 \pm 73.21$ & & $114.51 \pm 61.39$ & & 0.403 & \\
\hline \multirow[t]{2}{*}{ WASO (\%) } & M & $19.77 \pm 12.16$ & 0.167 & $21.62 \pm 13.18$ & 0.086 & $16.04 \pm 11.28$ & 0.093 & $<0.001$ & $b>c$ \\
\hline & $\mathrm{F}$ & $16.44 \pm 10.97$ & & $17.84 \pm 10.64$ & & $13.67 \pm 8.41$ & & 0.011 & $b>c$ \\
\hline \multirow[t]{2}{*}{ SE (\%) } & M & $77.29 \pm 13.75$ & 0.692 & $75.37 \pm 13.25$ & 0.214 & $82.22 \pm 11.85$ & 0.263 & $<0.001$ & $\mathrm{~b}<\mathrm{c}$ \\
\hline & $\mathrm{F}$ & $78.56 \pm 12.45$ & & $78.26 \pm 11.68$ & & $84.09 \pm 8.85$ & & $<0.001$ & $\mathrm{a}, \mathrm{b}<\mathrm{c}$ \\
\hline \multirow[t]{2}{*}{$\mathrm{AHI}(/ \mathrm{h})$} & M & $6.56 \pm 4.77$ & 0.341 & $34.24 \pm 21.28$ & 0.506 & $40.27 \pm 23.57$ & $<0.001$ & $<0.001$ & $\mathrm{a}<\mathrm{b}, \mathrm{c}$ \\
\hline & $\mathrm{F}$ & $5.63 \pm 4.82$ & & $32.03 \pm 17.37$ & & $31.41 \pm 26.93$ & & $<0.001$ & $\mathrm{a}<\mathrm{b}, \mathrm{c}$ \\
\hline \multirow[t]{2}{*}{ Total ArI (/h) } & M & $19.41 \pm 5.67$ & 0.046 & $31.40 \pm 15.82$ & 0.005 & $33.42 \pm 17.46$ & $<0.001$ & $<0.001$ & $a<b, c$ \\
\hline & $\mathrm{F}$ & $16.49 \pm 6.86$ & & $25.08 \pm 13.84$ & & $22.96 \pm 11.94$ & & $<0.001$ & $a<b, c$ \\
\hline \multirow[t]{2}{*}{ Resp ArI (/h) } & M & $4.82 \pm 3.79$ & $<0.001$ & $22.91 \pm 16.72$ & $<0.001$ & $27.07 \pm 19.37$ & $<0.001$ & $<0.001$ & $\mathrm{a}<\mathrm{b}, \mathrm{c}$ \\
\hline & $\mathrm{F}$ & $3.06 \pm 2.79$ & & $16.92 \pm 12.59$ & & $14.89 \pm 12.83$ & & $<0.001$ & $\mathrm{a}<\mathrm{b}, \mathrm{c}$ \\
\hline \multirow[t]{2}{*}{ RERA I (/h) } & M & $3.36 \pm 3.27$ & 0.007 & $2.16 \pm 2.29$ & 0.101 & $1.95 \pm 2.23$ & 0.175 & 0.002 & $a>b, c$ \\
\hline & $\mathrm{F}$ & $1.98 \pm 1.84$ & & $1.69 \pm 1.72$ & & $2.09 \pm 2.05$ & & 0.393 & \\
\hline \multirow[t]{2}{*}{ Spont ArI (/h) } & M & $9.68 \pm 4.50$ & 0.522 & $4.19 \pm 4.32$ & 0.891 & $2.91 \pm 3.12$ & 0.005 & $<0.001$ & $a>b>c$ \\
\hline & $\mathrm{F}$ & $9.38 \pm 5.72$ & & $4.45 \pm 4.82$ & & $4.21 \pm 3.96$ & & $<0.001$ & $a>b, c$ \\
\hline \multirow[t]{2}{*}{ MAI (/h) } & M & $0.57 \pm 0.80$ & 0.027 & $1.26 \pm 2.21$ & 0.860 & $0.84 \pm 2.26$ & 0.336 & 0.180 & - \\
\hline & $\mathrm{F}$ & $1.71 \pm 3.12$ & & $1.36 \pm 2.90$ & & $1.19 \pm 2.34$ & & 0.374 & - \\
\hline \multirow[t]{2}{*}{ PLMI (/h) } & M & $4.08 \pm 10.00$ & 0.027 & $15.24 \pm 27.28$ & 0.411 & $8.26 \pm 17.35$ & 0.717 & 0.001 & $\mathrm{~b}>\mathrm{a}, \mathrm{c}$ \\
\hline & $\mathrm{F}$ & $11.20 \pm 19.44$ & & $11.83 \pm 22.98$ & & $8.74 \pm 15.19$ & & 0.449 & - \\
\hline \multirow[t]{2}{*}{ Perceived TST (h) } & M & $4.42 \pm 1.57$ & 0.068 & $4.73 \pm 1.56$ & 0.208 & $5.21 \pm 1.54$ & 0.094 & 0.001 & $\mathrm{a}, \mathrm{b}<\mathrm{c}$ \\
\hline & $\mathrm{F}$ & $4.48 \pm 1.54$ & & $4.38 \pm 1.71$ & & $5.52 \pm 1.37$ & & $<0.001$ & $\mathrm{a}, \mathrm{b}<\mathrm{c}$ \\
\hline \multirow[t]{2}{*}{ Perceived SL (min) } & M & $56.09 \pm 58.68$ & 0.003 & $48.46 \pm 37.26$ & 0.542 & $32.24 \pm 31.98$ & 0.181 & $<0.001$ & $a, b>c$ \\
\hline & $\mathrm{F}$ & $57.28 \pm 48.16$ & & $53.01 \pm 51.92$ & & $36.15 \pm 35.62$ & & 0.001 & $a, b>c$ \\
\hline
\end{tabular}

Values are expressed as mean \pm standard deviation or numbers (\%). PI: primary insomnia, COMISA: comorbid insomnia with obstructive sleep apnea, OSA: obstructive sleep apnea, TIB: time in bed, TST: total sleep time, SL: sleep latency, REML: rapid eye movement sleep latency, WASO: wakefulness after sleep onset, SE: sleep efficiency, AHI: apnea-hypopnea index, ArI: arousal index, Resp.: respiratory, RERA: respiratory effort-related arousal, Spont.: spontaneous, MAI: movement arousal index, PLMI: periodic limb movement index

OSA군과 COMISA군 간에는 차이가 없었으며, RERA I는 $\mathrm{PI}$ 군이 가장 높았고, spont. ArI는 PI, COMSA, OSA군 순으 로 높았고, $\mathrm{PLMI}$ 는 COMISA군이 가장 높았다.

여성의 경우 TIB, REML, RERA I, MAI, PLMI 지표는 질 환간 유의한 차이가 없고 나머지 지표들은 유의한 차이를 보 였다. 사후분석 결과 TST는 OSA군이 COMISA군보다 길었 고, $\mathrm{SL}$ 은 $\mathrm{PI}$ 와 $\mathrm{COMISA}$ 군이 OSA군보다 길었고, WASO는 $\mathrm{COMISA}$ 군이 OSA군보다 길었고, $\mathrm{SE}$ 는 $\mathrm{OSA}$ 군이 가장 높
았다. AHI, total ArI, resp. ArI 지표는 COMISA군과 OSA군 이 PI군보다 높았고, spont. ArI는 PI군에서 가장 높았으며, perceived TST는 OSA군이 가장 높고, perceived SL은 OSA 군이 가장 낮았다(Table 2).

\section{고 찰}

본 연구는 불면 또는 폐쇄수면무호흡 관련 증상으로 내원 
한 환자들의 원인질환이 성별에 따라 차이가 있을 것으로 가 정하고 성별에 따른 최종 진단된 수면장애 분포를 조사하고, 주요 진단군인 PI, COMISA, OSA군에서 일반적 특성이나 수면다원검사 결과가 성별에 따라서 차이가 있는지를 확인 하였고, 성별에 따라 진단군 간 차이가 있는지를 확인하였다.

먼저 환자들의 주 호소 증상별 최종 진단 분포를 비교한 결 과를 살펴보면, 불면증 호소와 폐쇄수면무호흡 호소 환자들 모두 남녀간 최종 진단 분포는 유의한 차이가 있는 것으로 확 인되었다. 특히 불면증을 호소하는 남성 환자들의 경우 PI로 진단된 경우가 $22.5 \%$ 가 불과하고 절반이 넘는 $56.3 \%$ 가 OSA 기준에 합당하여 COMISA로 진단되었다. 반면 여성 불면증 호소 환자에서 PI 진단은 $48.6 \%$ 로 남성의 $22.5 \%$ 보다 두 배 이상 높기는 하였으나, 불면증 호소 여성환자에서도 PI 진단 은 절반에 미치지 못함을 고려하면 불면증 환자에서 다른 수 면장애가 동반될 가능성을 항상 염두에 두어야 한다. Zhang 등의 불면증과 OSA 공존에 관한 메타분석 연구에 따르면 불면증 환자에서 OSA 발생률은 13.6 68.75\%로 남성의 비 율이 높고 대상자의 나이가 많은 연구일수록 높은 발생률을 보였다. ${ }^{18}$ 불면증과 OSA의 몇몇 위험요소와 증상은 서로 반 대의 경향이 있어 여성 vs. 남성, 잠이 안 옴 vs. 주간졸음, 불 안(anxiety) vs. 진정(sedation)으로 구분되기도 하나, 불면증 과 OSA가 동시에 있는 COMISA군의 경우 이러한 특성을 동 시에 가지기 때문에 직관적으로 판단하는데 어려움이 있다. ${ }^{19}$ 본 연구에서도 불면증을 호소하는 환자 중 OSA로 진단된 COMISA 환자들은 OSA만 있는 OSA군에 비해 입면장애, 수면유지 어려움을 호소하는 빈도가 더 많고, 코골이나 무호 흡 호소는 더 적었는데, 이는 COMISA군에서 반복되는 수면 호흡 관련장애를 환자들은 수면유지장애로만 인지했을 가능 성이 있다. ${ }^{20}$ 따라서 불면증을 주소로 내원하더라도 OSA가 호발하는 만 50세 이상이면서 수면유지장애를 호소하는 남 성의 경우 OSA 동반 가능성이 있고, OSA 증상으로 인한 수 면유지장애를 호소하는 환자의 경우 positive airway pressure(PAP) 치료가 불면증을 개선하는데 도움이 되므로 진단 및 증상 개선을 위해 수면다원검사를 시행할 필요가 있다. ${ }^{21}$

다음으로 주 진단군인 PI, COMISA, OSA군 각각에서 남 녀간 일반적 특성이나 수면다원검사 결과에 차이가 있는지 살펴보겠다. 먼저 PI군에서는 여성이 남성보다 수면제 복용 비율이 높고, ISI 점수가 더 높고, 입면장애 호소 빈도가 높고, 평소 SL이 유의하게 더 길었지만, 수면다원검사 시 SL은 차 이가 없고 perceived SL만 긴 것으로 나타났다. 불면증 환자 들이 신경증(neuroticism), 내제화(internalization), 불안감, 완벽주의와 같은 성격특성 징후가 많은데, 이러한 성격특성 이 여성에서 더 흔해서 여성의 우울, 불안장애 비율을 증가시
킨다 한다. ${ }^{22,23}$ 우울, 불안감이 높은 경우 스트레스에 대처하 기 위한 자원이 부족해서 수면시간 과소평가를 매개하여 불 면증을 유발할 수 있는데, 객관적으로 정상수면시간을 취하 고 있음에도 주관적 수면시간을 저평가하는 수면상태 오각 성(sleep misperception)이 증가한다. ${ }^{24}$ 비록 본 연구에서 환 자들의 우울, 불안 점수를 조사하지는 않았지만, 불면증과 심 리적 디스트레스(psychiatric distress)의 사회적 계층과 성별 유형을 조사하기 위해 20년간 추적 조사한 연구에 따르면 여 성이 남성보다 불면증과 심리적 디스트레스를 모두 겪을 가 능성이 더 높은 것으로 보고하였다. ${ }^{25}$ 따라서 불면증 여성 환 자를 대상으로 치료적 접근을 할 때는 심리적 측면에 대한 접근도 함께 병행할 필요가 있다. 그 외 수면다원검사결과 상 총 각성지수, 호흡각성지수, 호흡노력과 관련된 각성지수 등은 남성이 더 높고, 운동각성지수와 주기적 사지 운동지수 는 여성이 더 높은 것으로 나타났다. 각성지수 중 호흡관련 지표가 남성이 더 높은 것은 해부생리학적 특성으로 인해 남 성이 여성보다 수면 중 호흡 시 확장기 근육 활성화 차이로 상기도 기능장애가 발생해 호흡저하가 더 증가하기 때문으 로 해석할 수 있다. ${ }^{26}$ 본 연구에서 남녀간 비교 시 $\mathrm{AHI}$ 를 보 정했음에도 총 각성지수 및 호흡각성지수는 PI군 뿐 아니라 COMISA, OSA군 모두에서 일관되게 남성이 더 높은 것을 알 수 있다.

COMISA군에서는 PI군에서 성별에 따른 차이를 보인 변 수에 추가로 낮잠 빈도는 남성이 $30.6 \%$ 로 여성의 $14.8 \%$ 보다 두 배로 증가하였고, 여성은 평소 수면시간이 남성보다 유의 하게 짧은 것으로 보고하였다. 이는 OSA 특성이 남성에서 일부 나타나는 것으로 생각해볼 수도 있지만, 성별에 따라 불면에 대처하는 인지행동적 특성의 차이일 가능성도 있다. ${ }^{27}$ 남성들은 좀 더 낮잠을 자려하고 낮잠이 불면증에 도움이 될 것이라는 잘못된 믿음이 있는 반면, 여성은 수면 직전 각성 (pre-sleep arousal)이 증가하여 남성보다 불면증 심각도를 더 심각하게 인지하므로 OSA와 같은 수면질환이 동반 시 수 면다원검사로 평가된 객관적 TST는 차이가 없음에도 여성 환자들에서 수면상태 오각성이 더 증가했을 가능성이 있다. ${ }^{27}$

$\mathrm{OSA}$ 군의 경우에도 여성이 남성보다 나이가 더 많고, 수면 제 복용 비율이 높고, ISI 점수가 높고, 입면장애 호소 빈도가 높았으며, 평소 SL이 유의하게 더 긴 것으로 보고하였다. 반 면 무호흡을 목격하는 빈도나 낮잠을 자는 빈도는 남성이 여 성보다 더 높은 것으로 조사되었다. 이는 여성 OSA 환자들 이 남성 OSA 환자보다 나이가 적고 OSA 특이적 증상보다 비특이적 증상을 호소하는 빈도가 높다는 선행연구와 유사 한 결과이다. ${ }^{9}$ 수면다원검사 결과 다른 질환과 마찬가지로 총 각성지수, 호흡각성지수는 남성이 더 높고, 자발각성지수와 
TST는 남성이 더 적은 것으로 나타났다. OSA 남성의 수면다 원검사에서 TST 시간은 평균 5.75시간으로 검사 다음날 주 관적으로 평가한 perceived TST 5.21시간과 비교해 약 0.4 시간 차이인 반면, OSA 여성 환자는 6.22시간과 5.52시간으 로 0.7 시간의 격차를 보여 OSA에서도 여성이 남성보다 수면 상태 오각성이 더 큰 것을 알 수 있다.

마지막으로 PI, COMISA, OSA 세 군간 비교를 남녀 성별 로 나누어 비교한 결과를 논의하고자 한다. 주관적 증상을 세부적으로 살펴보면 ISI는 남녀 모두에서 PI군과 COMISA 군이 OSA군보다 더 높은 점수를 보였고, 특히 평소 수면잠 복기(habitual sleep latency)가 세 군 모두 여성에서 남성보 다 길었고, 입면장애 호소도 여성에서 유의하게 많은 것으로 나타났다. 여성이 남성보다 일주기가 짧고 빠르며, ${ }^{28}$ 멜라토 닌분비시작시점(dim light melatonin onset)도 이른 경향을 보인다는 연구에 근거한다면, ${ }^{29}$ 비록 본 연구에서 대상자의 일주기유형이나, 평소 취침시간이나 기상시간을 조사하지는 않았지만 수면장애를 호소하는 여성이 남성보다 좀 더 일찍 잠자리에 들어가나, 불면증으로 잠을 이루지 못해 입면장애 를 더 많이 호소했을 가능성이 있다. 또한 노인 여성의 경우, 동년배 남성보다 멜라토닌 수치가 더 낮아 수면의 어려움을 더 많이 호소한다는 보고도 있는데, ${ }^{30}$ 본 연구대상자 중 여성 이 남성보다 나이가 많은 군이 있어 입면장애 빈도가 더 많 았을 가능성도 있겠다.

주간졸음척도인 $\mathrm{ESS}$ 는 OSA군에서 가장 높았지만, $\mathrm{PI}$ 군과 COMISA군 간에는 유의한 차이가 없었고, 낮잠을 잔다고 보 고한 빈도도 세 군간에 차이는 없었다. 불면증 환자에서 불 면증상은 신경생리학적 과각성(hyperarousal)과 심리적, 행 동적 과정에서의 상호작용에 의해 발생하는데, ${ }^{31}$ 불면증상을 호소하는 COMISA군의 경우는 수면호흡장애에 의한 각성이 생물-생리학적 기전(bio-physiological mechanism)에 의해 불면증상에 영향을 주고, 이러한 불면증상은 다시 정신-생리 학적 기전(psycho-physiological mechanism)에 의해 수면 호흡장애에 영향을 주는 악순환을 반복하여 불면증과 유사 한 증상을 호소할 수 있다. ${ }^{20}$ 본 연구에서도 수면다원검사 당 시 환자가 지각하는 수면시간이 PI군과 COMISA군에서 약 1 시간 정도 적은 것으로 보고한 바 불면증의 특성이 강한 것 을 알 수 있다. 따라서 COMISA군에게 OSA 치료 목적으로 $\mathrm{PAP}$ 을 적용하기 전에 불면증상에 대해 인지행동치료를 병 행하거나 선행하는 것이 PAP 순응도를 올리는데 도움이 될 것이다. ${ }^{32}$ 특히 COMISA 환자 중 중증 OSA가 동반된 남성 환자는 동일한 중증도의 여성 환자보다 PAP 순응도가 더 낮은 것으로 보고되고 있는데, ${ }^{11}$ 본 연구의 COMISA 남성 환자에서 ISI 점수가 PI 남성군과 유사하고 약물 복용력은
PI 남성 환자보다 더 높은 것을 고려하면 남성 COMISA 환 자들은 폐쇄수면무호흡보다 불면증 성향이 더 강한 유형 (phenotype)일 수 있으므로 좀 더 적극적인 불면증 치료가 필요할 것이다.

$\mathrm{COMISA}$ 군에서 주관적 평가의 특성은 PI군과 유사한 반 면, 수면다원검사에서 COMISA군의 특성은 OSA군과 유사 한 특성을 보였다. COMISA군과 OSA군 모두 AHI가 평균 $30 / \mathrm{h}$ 이 넘었으며, 각성지수도 $\mathrm{PI}$ 군에 비해 유의하게 높은 것으로 나타났다. COMISA의 진단이 어려운 것은 두 가지 수면 질환의 증상을 공유하기 때문인데, 일단 환자가 불면증 이나 OSA로 진단이 되면 다른 질환은 평가하지 않을 수 있 다. ${ }^{33} \mathrm{COMISA}$ 군의 각성이 호흡관련 요인이 큰 점을 고려하 면 OSA 치료를 위해 적극적인 접근이 필요할 것이다.

본 연구의 제한점으로는 단일 상급종합병원 수면센터에서 시행되었으며, 불면증을 호소하는 환자들은 수면호흡장애 관련 증상이 전혀 없는 경우는 아직 수면다원검사에 대한 급 여 적용을 받지 못하고 있어 선택 편위(selection bias)가 있을 수 있다. 또한 진료과별로 환자를 접근하는 방식에 차이가 있을 수 있다. 수면장애 환자들은 신경과, 이비인후과, 정신 건강의학과를 비롯한 다양한 진료과를 통해 수면다원검사가 의뢰되는데 진료과별로 환자의 주 호소 증상에 대한 판단이 차이가 있을 가능성이 있으나, 연구가 후향적 의무기록 조사 연구라 환자의 주요 수면장애 증상을 일관되게 사정하지 못 한 점이 있다. 그럼에도 불구하고 불면증상을 호소하는 환자 중 상당수가 OSA가 동반됨을 확인할 수 있었고, 수면다원검 사와 같은 객관적 검사가 정확한 진단과 치료적 접근을 하는 데 필요하다는 것을 확인한 것에 의의가 있다.

이상을 종합하여 보았을 때, 여성 수면장애 환자들은 남성 환자들에 비해 불면증 특이적 증상 호소가 더 강하고 평소 수 면잠복기가 길다고 호소하나 객관적 수면검사에서는 큰 차 이가 없어 수면상태 오각성이 큰 성향을 보였고, 남성의 경 우에는 불면증 여부와 상관없이 OSA가 동반된 경우 낮잠을 더 많이 자려고 하는 경향이 있음을 확인하였다. COMISA 남성군에서는 불면증 특성과 OSA 특성이 혼재되어 있으므 로, 코골이나 무호흡 증상이 없더라도 낮잠을 자거나 수면유 지장애의 어려움을 호소한다면 OSA가 동반되었음을 의심하 여 적극적인 검사가 필요할 것이다. 불면증 환자에서 OSA가 감별되지 않을 때 불면증 인지행동치료 시 요구되는 수면제 한요법이 주간졸음을 더 악화시킬 수 있고, 불면증 개선을 위해 사용되는 약물도 OSA 증상을 악화시킬 수 있다. ${ }^{20}$ 본 연구는 불면증에서도 객관적 검사가 필요함을 보여주는 근 거를 제시하고 있어 임상적 의의가 있다고 생각된다. 


\section{Acknowledgments}

This study was supported by Samsung Medical Center Grant (\#OTC1190671).

\section{Conflicts of Interest}

The authors have no potential conflicts of interest to disclose.

\section{ORCID iDs}

Su Jung Choi

Dongyeop Kim

Yoonha Hwang

Hyunjin Jo

Eun Yeon Joo https://orcid.org/0000-0003-2171-7441 https://orcid.org/0000-0001-6045-0693 https://orcid.org/0000-0002-2624-9336 https://orcid.org/0000-0001-9563-1849 https://orcid.org/0000-0003-1233-959X

\section{Author Contributions}

Conceptualization: Eun Yeon Joo, Su Jung Choi. Data curation: Eun Yeon Joo, Su Jung Choi, Dongyeop Kim. Formal analysis: Su Jung Choi, Hyunjin Jo, Dongyeop Kim. Investigation: Su Jung Choi, Yoonha Hwang. Methodology: Su Jung Choi, Eun Yeon Joo, Hyunjin Jo. Supervision: Eun Yeon Joo. Writing_original draft: Su Jung Choi. Writing-review \& editing: Eun Yeon Joo, Su Jung Choi.

\section{REFERENCES}

1. American Academy of Sleep Medicine. International Classification of Sleep Disorders-Third Edition (ICSD-3). Darien: American Academy of Sleep Medicine, 2014.

2. Morin CM, Benca R. Chronic insomnia. Lancet 2012;379:1129-1141. https://doi.org/10.1016/S0140-6736(11)60750-2.

3. Zhang B, Wing YK. Sex differences in insomnia: a meta-analysis. Sleep 2006;29:85-93. https://doi.org/10.1093/sleep/29.1.85.

4. Kim KW, Kang SH, Yoon IY, et al. Prevalence and clinical characteristics of insomnia and its subtypes in the Korean elderly. Arch Gerontol Geriatr 2017;68:68-75. https://doi.org/10.1016/j.archger.2016.09.005.

5. Marin JM, Carrizo SJ, Vicente E, Agusti AG. Long-term cardiovascular outcomes in men with obstructive sleep apnoea-hypopnoea with or without treatment with continuous positive airway pressure: an observational study. Lancet 2005;365:1046-1053. https://doi.org/10.1016/ S0140-6736(05)71141-7.

6. Choi SJ, Suh S, Ong J, Joo EY. Sleep misperception in chronic insomnia patients with obstructive sleep apnea syndrome: implications for clinical assessment. J Clin Sleep Med 2016;12:1517-1525. https://doi. org/10.5664/jcsm.6280.

7. Luyster FS, Buysse DJ, Strollo PJ Jr. Comorbid insomnia and obstructive sleep apnea: challenges for clinical practice and research. J Clin Sleep Med 2010;6:196-204. https://doi.org/10.5664/jcsm.27772.

8. Heinzer R, Marti-Soler H, Marques-Vidal P, et al. Impact of sex and menopausal status on the prevalence, clinical presentation, and comorbidities of sleep-disordered breathing. Sleep Med 2018;51:29-36. https://doi.org/10.1016/j.sleep.2018.04.016.

9. Pyun SY, Choi SJ, Jo H, Hwang Y, Cho JW, Joo EY. Gender differences in Korean patients with obstructive sleep apnea. Sleep Med Res 2020 Oct 23 [Epub]. Available at: https://doi.org/10.17241/smr.2020.00556.

10. Voderholzer U, Al-Shajlawi A, Weske G, Feige B, Riemann D. Are there gender differences in objective and subjective sleep measures? A study of insomniacs and healthy controls. Depress Anxiety 2003;17:162-172. https://doi.org/10.1002/da.10101.

11. Loução-de-Amorim I, Bentes C, Peralta AR. Men and women with chronic insomnia disorder and OSAS: different responses to CPAP. Sleep Sci 2019;12:190-195. https://doi.org/10.5935/1984-0063.20190085.

12. Cho YW, Song ML, Morin CM. Validation of a Korean version of the insomnia severity index. J Clin Neurol 2014;10:210-215. https://doi. org/10.3988/jcn.2014.10.3.210.
13. Cho YW, Lee JH, Son HK, Lee SH, Shin C, Johns MW. The reliability and validity of the Korean version of the Epworth sleepiness scale. Sleep Breath 2011;15:377-384. https://doi.org/10.1007/s11325-010-0343-6.

14. Berry RB, Brooks R, Gamaldo C, et al. AASM scoring manual updates for 2017 (version 2.4). J Clin Sleep Med 2017;13:665-666. https://doi. org/10.5664/jcsm. 6576 .

15. Kang MR, Choi SJ, Joo EY. Sleep disorders documented by night polysomnography in patients with chronic insomnia disorder. J Korean Neurol Assoc 2018;36:1-8. https://doi.org/10.17340/jkna.2018.1.1.

16. Seong MJ, Jung AR, Park HR, Choi SJ, Joo EY. Dream recall frequency and sleep in patients with rapid eye movement sleep behavior disorder. J Sleep Med 2017;14:55-60. https://doi.org/10.13078/jsm.17008.

17. Morgenthaler TI, Lee-Chiong T, Alessi C, et al. Practice parameters for the clinical evaluation and treatment of circadian rhythm sleep disorders. An American Academy of Sleep Medicine report. Sleep 2007;30: 1445-1459. https://doi.org/10.1093/sleep/30.11.1445.

18. Zhang Y, Ren R, Lei F, et al. Worldwide and regional prevalence rates of co-occurrence of insomnia and insomnia symptoms with obstructive sleep apnea: a systematic review and meta-analysis. Sleep Med Rev 2019;45:1-17. https://doi.org/10.1016/j.smrv.2019.01.004.

19. Sweetman A, Lack L, Bastien C. Co-morbid insomnia and sleep apnea (COMISA): prevalence, consequences, methodological considerations, and recent randomized controlled trials. Brain Sci 2019;9:371. https:// doi.org/10.3390/brainsci9120371.

20. Janssen HCJP, Venekamp LN, Peeters GAM, Pijpers A, Pevernagie DAA. Management of insomnia in sleep disordered breathing. Eur Respir Rev 2019;28:190080. https://doi.org/10.1183/16000617.0080-2019.

21. Glidewell RN, Renn BN, Roby E, Orr WC. Predictors and patterns of insomnia symptoms in OSA before and after PAP therapy. Sleep Med 2014;15:899-905. https://doi.org/10.1016/j.sleep.2014.05.001.

22. van de Laar M, Verbeek I, Pevernagie D, Aldenkamp A, Overeem S. The role of personality traits in insomnia. Sleep Med Rev 2010;14:61-68. https://doi.org/10.1016/j.smrv.2009.07.007.

23. Weisberg YJ, Deyoung CG, Hirsh JB. Gender differences in personality across the ten aspects of the big five. Front Psychol 2011;2:178. https:// doi.org/10.3389/fpsyg.2011.00178.

24. Fernandez-Mendoza J, Calhoun SL, Bixler EO, et al. Sleep misperception and chronic insomnia in the general population: role of objective sleep duration and psychological profiles. Psychosom Med 2011;73:8897. https://doi.org/10.1097/PSY.0b013e3181fe365a.

25. Green MJ, Espie CA, Benzeval M. Social class and gender patterning of insomnia symptoms and psychiatric distress: a 20-year prospective cohort study. BMC Psychiatry 2014;14:152. https://doi.org/10.1186/1471244X-14-152.

26. Pillar G, Malhotra A, Fogel R, Beauregard J, Schnall R, White DP. Airway mechanics and ventilation in response to resistive loading during sleep: influence of gender. Am J Respir Crit Care Med 2000;162:16271632. https://doi.org/10.1164/ajrccm.162.5.2003131.

27. Sidani S, Guruge S, Fox M, Collins L. Gender differences in perpetuating factors, experience and management of chronic insomnia. J Gend Stud 2019;28:402-413. https://doi.org/10.1080/09589236.2018.1491394.

28. Duffy JF, Cain SW, Chang AM, et al. Sex difference in the near-24hour intrinsic period of the human circadian timing system. Proc Natl Acad Sci U S A 2011;108 Suppl 3:15602-15608. https://doi.org/10.1073/ pnas. 1010666108.

29. Van Reen E, Sharkey KM, Roane BM, et al. Sex of college students moderates associations among bedtime, time in bed, and circadian phase angle. J Biol Rhythms 2013;28:425-431. https://doi.org/10.1177/ 0748730413511771.

30. Obayashi K, Saeki K, Tone N, et al. Lower melatonin secretion in older females: gender differences independent of light exposure profiles. $J$ Epidemiol 2015;25:38-43. https://doi.org/10.2188/jea.JE20140035.

31. Levenson JC, Kay DB, Buysse DJ. The pathophysiology of insomnia. Chest 2015;147:1179-1192. https://doi.org/10.1378/chest.14-1617.

32. Sweetman A, Lack L, Catcheside PG, et al. Cognitive and behavioral 
Choi SJ et al.

therapy for insomnia increases the use of continuous positive airway pressure therapy in obstructive sleep apnea participants with comorbid insomnia: a randomized clinical trial. Sleep 2019;42:zsz178. https:// doi.org/10.1093/sleep/zsz178.
33. Brock MS, Mysliwiec V. Comorbid insomnia and sleep apnea: a prevalent but overlooked disorder. Sleep Breath 2018;22:1-3. https://doi. org/10.1007/s11325-018-1628-4. 